\title{
Giant abdominal liposarcoma
}

\author{
Popli MB ${ }^{1 *}$ and Popli $\mathrm{V}^{2}$ \\ ${ }^{1}$ Department of Radiological Imaging, Institute of Nuclear Medicine and Allied Sciences (INMAS), Lucknow Road, Delhi, India \\ ${ }^{2}$ Department of Pediatrics, BSA hospital, Rohini, Delhi, India
}

\begin{abstract}
Liposarcoma is the second most common soft tissue sarcoma type in adults. These tumors take their origin from primitive mesenchymal cells. In abdomen they generally arise from the retroperitoneum. Here we report a case of Giant Liposarcoma of the abdomen arising from the mesentery.
\end{abstract}

\section{Case report}

A 38 years old male was referred with a complaint of fullness of abdomen and vague abdominal pain. There was nothing significant in the present or past history. There was no complaint of nausea, vomiting, dyspepsia or diarrhea. On physical examination abdomen was found to be distended. There was mild abdominal tenderness. No definite lump could be palpated.

On ultrasound examination, it was found that whole of the abdomen was filled with an echogenic mass. The mass also extended into the pelvis. In addition, a well-defined hypoechoic SOL was seen in the umbilical region (Figure 1). Visualization of other organs was quite difficult. Grossly liver and gall bladder appeared normal though displaced laterally. Bilateral kidneys and spleen showed no gross abnormality. There was no evidence of free fluid. Retroperitoneal area could not be visualized.

CECT abdomen was carried out to delineate the pathology better. A large lobulated, low attenuating, fat density mass was seen to occupy most of the abdominal cavity (Figure 2). It extended into the pelvis and extrinsic impression was seen on the anterior bladder wall. Septations were seen within the mass. Bowel loops were displaced to the left and also encased at places by this mass. Within this fat density mass, another well defined heterogeneously enhancing complex lesion, was seen in the region of the mesentery (Figure 3).

Liver appeared normal. There was no evidence of any focal liver pathology. No IHBR dilatation was seen. GB, Pancreas, Spleen were normal. Both kidneys appeared to be normal and were noted to excrete the contrast. There was no evidence of Ascitis. CT image morphology was suggestive of a large abdominal Lipomatous Tumor, mesentery being the probable site of origin.

FNAC under US guidance was inconclusive. CT guided FNAC of the mesenteric soft tissue mass showed only fresh blood and small clumps of fat cells. No inflammatory cells were seen. No malignant cells were seen.

Patient was taken up for surgery. Histopathology report was that of a Liposarcoma with mixed histological pattern.

\section{Discussion}

Liposarcoma are the second most common sarcoma in adult next to Malignant Fibrous Histiocytoma. They comprise of $20 \%$ of all malignant soft tissue tumors. Liposarcoma are classified as-well differentiated, myxoid, pleomorphic, round cell and dedifferentiated tumors. There are also mixed forms which are a combination of multiple histological types. Overall, liposarcoma is very rare accounting for $0.2-0.3 \%$ of all malignancies $[1,2]$.

Liposarcoma is a tumor of adults with a peak incidence between the age of 50-65 years. The commonest site, 56\%, for liposarcoma is popliteal fossa and thigh. $15-20 \%$ are located in retroperitoneum $[3,4]$. Liposarcoma arising from the mesentery is rare.

Liposarcoma grows slowly and in a silent manner [5]. As a result, the patient's history is not very reliable about the clinical duration of the mass. Patient with abdominal liposarcoma report to the hospital only when the tumor has grown to a considerable size and causes problems like compression of bowel, tenderness and heaviness of the abdomen $[6,7]$. This results into late diagnosis. Diffuse and gradual abdominal enlargement is seen. Weight loss, despite of increasing abdominal girth, is a prominent feature. The patient appears emaciated with a large abdomen.

Imaging modalities plays a role in evaluating the mass [8-10]. Ultrasound helps in confirmation of the mass when doubt exists. CT, in addition to the preoperative evaluation of the tumor provides detailed morphological information about this low attenuating lipomatous tumor. Nodularity, irregular margins, area of enhancement and necrosis within the mass are suggestive of liposarcoma.

The treatment of choice for abdominal liposarcoma is surgical resection, as either radiotherapy or chemotherapy has not proved beneficial in increasing the long-term survival of the patient $[11,12]$. As this tumor has high rate of recurrence and poor prognosis due to uncontrolled local growth within abdominal cavity, an aggressive surgical management is advised. Follow up imaging scans are advised to detect recurrence at the earliest.

${ }^{*}$ Correspondence to: Manju Bala Popli, Department of Radiological Imaging, INMAS, Delhi, India, Tel: 011-2390528; Fax: 011-23930396; E-mail: manju_popli@rediffmail.com

Key words: giant, abdomen, liposarcoma

Received: March 05, 2018; Accepted: March 22, 2018; Published: March 26, 2018 


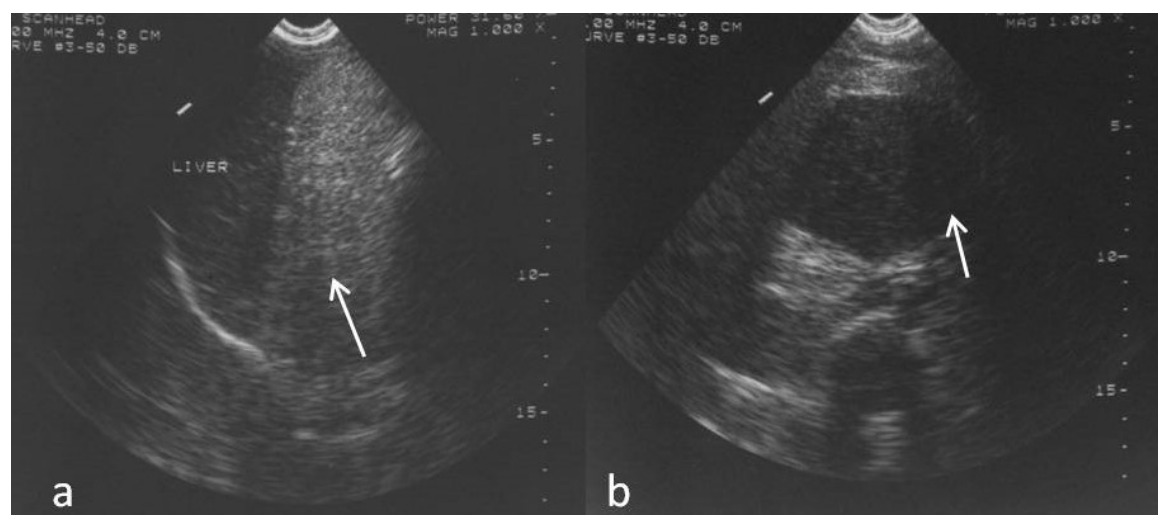

Figure 1. a) Large echogenic mass in abdomen on US. Liver grossly normal. b) Well defined hypoechoic mass seen in the umbilical region on US

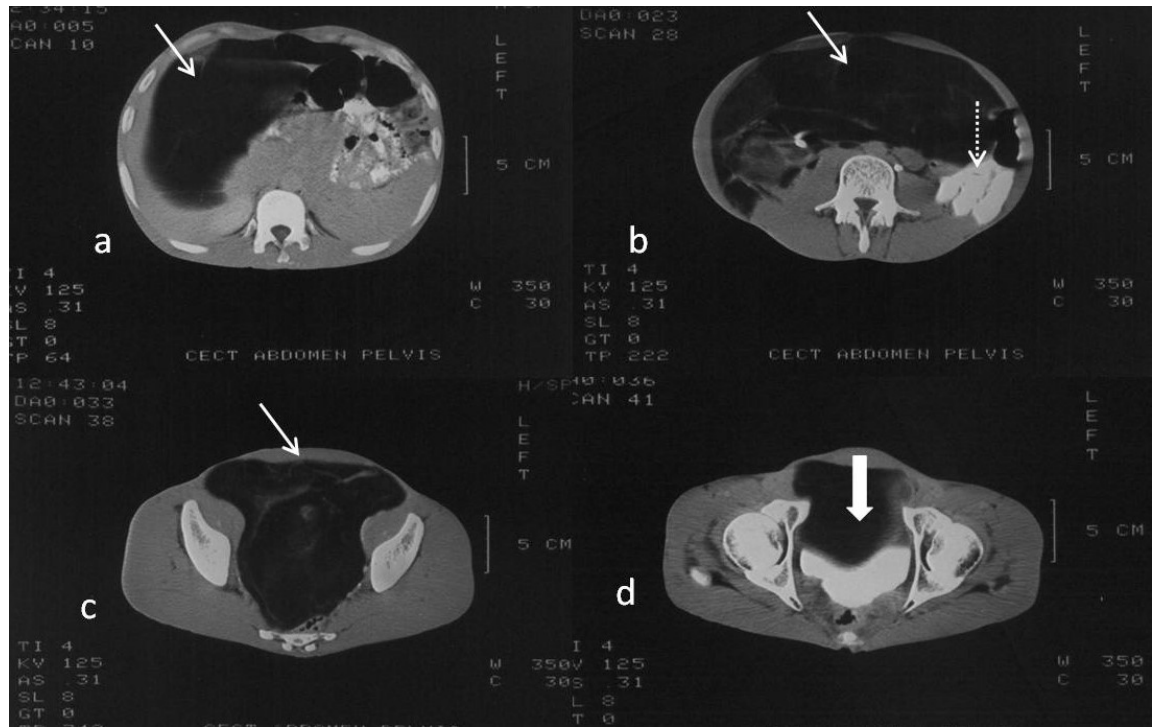

Figure 2. (a-d) CECT Abdomen. Scans show a huge low attenuating lipomatous mass occupying whole of the abdomen and pelvis (arrow). Bowel is seen displaced to one side (dotted arrow). Extrinsic impression on bladder is seen (thick arrow)

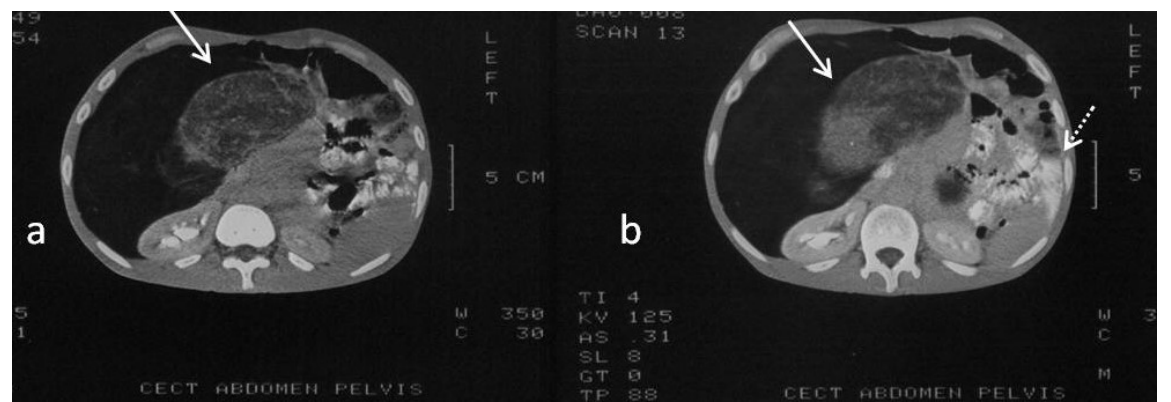

Figure 3. (a-b) CECT abdomen Scans show a heterogeneously enhancing lesion, with a well defined soft tissue component, in the region of the mesentery (arrow). Bowel is displaced to left side of the abdomen (dotted arrow)

\section{Conflict of interest}

Nil

\section{Funding}

Nil

\section{References}

1. Hashimoto Y, Hatakeyama S, Tachiwada T, Yoneyama T, Koie T, et al. (2010) Surgical treatment of a giant liposarcoma in a Japanese man. Adv Urol 2010: 943073. [Crossref]
2. Caizzone A, Saladino E, Fleres F, Paviglianiti C, Iaropoli F, et al. (2015) Giant retroperitoneal liposarcoma: Case report and review of the literature. Int $J$ Surg Case Rep 9: 23-26. [Crossref]

3. Elizabeth Montgomery (2006) Soft tissue tumors. In: Silverberg SG (Eds.) Silverberg's Principles and Practice of Surgical pathology and Cytopathology. 4th Ed. Churchill Livingstone Elsevier. Elsevier Inc, 307-418.

4. Brennan MF, Caser ES, Harrison LB (1997) Soft tissue sarcoma. In: DeVita VT, Hellman S, Rosenberg SA (Eds.) Cancer- Principles and practice of oncology. 5th Ed. Lippincott- Raven publishers 1738- 1788.

5. Drevelegas A, Pilavaki M, Chourmouzi D (2004) Lipomatous tumors of soft tissue: MR appearance with histological correlation. Eur J Radiol 50: 257-267. [Crossref] 
6. Hrabar D, Sulentic P, Tonasic V, Beslin MB, Bilic B, et al. (2007) Giant "Lipoma- Like" liposarcoma of the Retroperitoneum: A case report. Acta Clin Croat 46: 321-323.

7. Sherer DM, Lysikiewicz A, Chambers JT, Frager D, Eliakim R, et al. (2002) Large mesenteric lipoma ultrasonographically mimicking a mature cystic teratoma during pregnancy. J Ultrasound Med 21: 473-476. [Crossref]

8. Yildirim A, Basok E, Gulpinar T (2005) A giant retroperitoneal Lipoma: A case report. Marmara Medical J 18: 140-142.

9. Inoue K, Higaki Y, Yoshida H (2005) Giant retroperitoneal liposarcoma. Int J Urol 12 220-222. [Crossref]
10. Bradley JC, Caplan R (2002) Giant retroperitoneal sarcoma: a case report and review of the management of retroperitoneal sarcomas. Am Surg 68: 52-56. [Crossref]

11. Serpell JW, Chen RY (2007) Review of large deep lipomatous tumours. ANZ J Surg 77: 524-529. [Crossref]

12. Leão P, Vilaça S, Oliveira M, Falcão J (2012) Giant recurrent retroperitoneal liposarcoma initially presenting as inguinal hernia: Review of literature. Int J Surg Case Rep 3: 103-106. [Crossref]

Copyright: (C2018 Popli MB. This is an open-access article distributed under the terms of the Creative Commons Attribution License, which permits unrestricted use, distribution, and reproduction in any medium, provided the original author and source are credited. 